\title{
Reduced Expression of Cardiac Ryanodine Receptor Protects against Stress-induced Ventricular Tachyarrhythmia, but Increases the Susceptibility to Cardiac Alternans
}

Xiaowei Zhong ${ }^{1, \mathrm{a}}$, Alexander Vallmitjana ${ }^{2}$, Bo Sun $^{1, \mathrm{~b}}$, Zhichao Xiao ${ }^{1}$, Wenting Guo ${ }^{1, \mathrm{a}}$, Jinhong Wei $^{1, c}$, Mingke Ni ${ }^{1}$, Yongxiang Chen ${ }^{1}$, Edward R. O’Brien ${ }^{1}$, Anne M. Gillis ${ }^{1}$, Masahiko Hoshijima $^{3}$, Hiroshi Takeshima ${ }^{4}$, Leif Hove-Madsen ${ }^{5}$, Raul Benitez ${ }^{2}$, Darrell Belke ${ }^{1}$, and S.R. Wayne Chen ${ }^{1, \mathrm{~d}, *}$

From the ${ }^{1}$ Libin Cardiovascular Institute of Alberta, Department of Physiology and Pharmacology, University of Calgary, Calgary, Alberta T2N 4N1, Canada, ${ }^{2}$ Department of Automatic Control, Universitat Politècnica de Catalunya, 08034, Barcelona, Spain, ${ }^{3}$ Department of Medicine and Center for Research in Biological Systems, University of California, San Diego, CA 92093, USA, ${ }^{4}$ Department of Biological Chemistry, Graduate School of Pharmaceutical Sciences, Kyoto University, Kyoto, 606-8501, Japan, and ${ }^{5}$ Cardiovascular Research Centre CSIC-ICCC and IIB Sant Pau, Hospital de Sant Pau, 08025, Barcelona, Spain

Running Title: Reducing RyR2 expression suppresses VT but enhances alternans

${ }^{a}$ XZ, WG, recipients of the Alberta Innovates-Health Solutions (AIHS) Studentship Award. ${ }^{b}$ BS, recipient of the Heart and Stroke Foundation of Canada Junior Fellowship Award and the Alberta Innovates-Health Solutions (AIHS) Fellowship Award.

${ }^{\mathrm{c} J W}$, recipient of the Libin Cardiovascular Institute of Alberta and Cumming School of Medicine Postdoctoral Fellowship Award.

${ }^{\mathrm{d}}$ SRWC, AIHS Scientist.

*To whom correspondence should be addressed. S.R. Wayne Chen, 3330 Hospital Drive N.W., Calgary, Alberta, Canada, T2N 4N1. Tel.: 403-220-4235; e-mail: $\underline{\text { swchen@ucalgary.ca }}$

Keywords: Ventricular tachyarrhythmia, $\mathrm{Ca}^{2+}$ alternans, action potential duration alternans, hypertrophy, sudden death, sarcoplasmic reticulum, cardiac ryanodine receptor 


\begin{abstract}
Reduced protein expression of the cardiac ryanodine receptor (RyR2) is thought to affect the susceptibility to stress-induced ventricular tachyarrhythmia (VT) and cardiac alternans, but direct evidence for the role of RyR2 protein expression in VT and cardiac alternans is lacking. Here we used a mouse model $\left(c r r^{\mathrm{ml}}\right)$ that expresses a reduced level of the RyR2 protein to determine the impact of reduced RyR2 protein expression on the susceptibility to VT, cardiac alternans, cardiac hypertrophy, and sudden death. Electrocardiography (ECG) analysis revealed that after the injection of relatively high doses of caffeine and epinephrine (agents commonly used for stress test), wildtype (WT) mice displayed long-lasting VTs, whereas, the $\mathrm{crr}^{\mathrm{m} 1}$ mutant mice exhibited no VTs at all, indicating that the $c r r^{\mathrm{m} 1}$ mutant mice are resistant to stress-induced VTs. Intact heart $\mathrm{Ca}^{2+}$ imaging and action potential (AP) recordings showed that the $c r r^{\mathrm{m} 1}$ mutant mice are more susceptible to fast-pacing induced $\mathrm{Ca}^{2+}$ alternans and AP duration alternans compared with WT mice. The $c r r^{\mathrm{m} 1}$ mutant mice also showed increased heart weight-to-body weight ratio and incidence of sudden death at young ages. Furthermore, the $c r r^{\mathrm{m} 1}$ mutant hearts displayed altered $\mathrm{Ca}^{2+}$ transients with increased time-to-peak and decay time ( $\left.\mathrm{T}_{50}\right)$, increased ventricular wall thickness and ventricular cell area compared with WT hearts. These results indicate that reduced RyR2 protein expression suppresses stress-induced VTs, but enhances the susceptibility to cardiac alternans, hypertrophy, and sudden death.
\end{abstract}




\section{INTRODUCTION}

Ryanodine receptor type 2 (RyR2) is the major $\mathrm{Ca}^{2+}$ release channel expressed in the sarcoplasmic reticulum (SR) of cardiac muscle cells. It plays an essential role in excitationcontraction coupling by governing $\mathrm{SR} \mathrm{Ca}^{2+}$ release, which causes muscle contraction [1]. Given its important role in cardiac function, dysfunction of RyR2 can lead to various cardiac disorders. Indeed, a large number of naturally occurring mutations in RyR2 have been associated with catecholaminergic polymorphic ventricular tachycardia (CPVT), atrial or ventricular fibrillation, hypertrophic or dilated cardiomyopathies, and sudden cardiac arrest $[2,3]$. RyR2 dysfunction as a result of abnormal post-translational modifications have also been implicated in various cardiac conditions, such as heart failure [4-6]. Although the molecular mechanisms by which RyR2 mutations and post-translational modifications cause diseases are not completely understood, it is generally believed that most of these RyR2 mutations or modifications alter channel activation or inactivation, leading to enhanced or suppressed RyR2 activity [2, 5-12].

Besides alterations in the activation or inactivation properties of the channel, changes in the protein expression of RyR2 have also been implicated in the pathogenesis of cardiac diseases [1316]. It has been shown that the level of RyR2 protein expression is significantly increased in patients with paroxysmal atrial fibrillation (AF) and in a mouse model of AF [17, 18]. These observations suggest that enhanced protein expression of RyR2 may be associated with an increased susceptibility to AF. On the other hand, ablating the expression of RyR2 by genetargeted knock-out (KO) resulted in embryonic lethality [19], while heart-specific, conditional KO of RyR2 led to cardiac hypertrophy and sudden death [20]. Reduced RyR2 protein expression has also been proposed to be involved in cardiac alternans. Wan et al [21] showed that endocardial myocytes, which express less RyR2 and SERCA2a proteins, are more susceptible to cardiac alternans than epicardial myocytes, which express higher levels of RyR2 and SERCA2a proteins. Furthermore, reduction in RyR2 protein expression may affect the susceptibility to stress-induced ventricular arrhythmias. Some CPVT-linked RyR2 mutations, such as the deletion of exon-3 and the point mutation G357S, were found to markedly reduce the expression of the RyR2 protein [2224]. Interestingly, the clinical phenotypes and severities of individuals carrying these mutations appear to be highly variable, some of them are even asymptomatic [23, 25-28]. These observations suggest that reduced RyR2 protein expression may contribute to the incomplete penetrance of CPVT phenotypes. However, it is important to note that despite their potential association, direct evidence for the link between reduced RyR2 protein expression and CPVT susceptibility or cardiac alternans has yet to be established.

In the present study, we employed a mouse model [19] in which the protein expression of the wildtype RyR2 is substantially reduced to investigate the impact of reduced RyR2 protein expression on CPVT, cardiac alternans, cardiac hypertrophy, and sudden death. We demonstrated for the first time that reducing the level of the RyR2 protein protects against CPVT, but enhances the susceptibility to $\mathrm{Ca}^{2+}$ alternans and action-potential duration alternans. Reduced RyR2 protein expression also resulted in cardiac hypertrophy and sudden death, as reported previously [20]. Our data suggest that reducing the protein expression of RyR2 may represent an effective approach for suppressing CPVT. 


\section{EXPERIMENTAL PROCEDURES Animal studies}

All animal studies were approved by the Institutional Animal Care and Use Committees at the University of Calgary and were performed in accordance with US National Institutes of Health guidelines. The RyR2-targeted mutant mouse $\left(\mathrm{crr}^{\mathrm{ml}}\right)$ was generated as described previously [19]. Adult homozygous $\mathrm{crr}^{\mathrm{ml}}$ mutant mice and wildtype (WT) littermates (8-10 weeks) in the 129-E mouse background (Charles River) were used for all experiments. Note that in the study by Takeshima et al [19], two RyR2 mutant mouse lines were generated: one is a RyR2-targeted mutant mouse called $c r r^{\mathrm{m} 1}$ and the other is a Cre-recombined RyR2 mutant mouse called $c r r^{\mathrm{m} 2}$. In the $c r r^{\mathrm{ml}}$ mutant mice, a loxP sequence was inserted into the 5'-untranslation region in exon 1, and a cassette containing a loxP sequence, the green fluorescence protein (GFP) cDNA, and the neomycin resistance gene (Neo) was inserted into the first intron of the mouse ryr 2 gene. In the $\mathrm{crr}^{\mathrm{m} 2}$ mutant mice, the DNA sequence between the two loxP sites has been removed using the Cremediated recombination, resulting in the deletion of exon 1 and thus the RyR2 knockout (KO). Takeshima et al. used the $c r r^{\mathrm{m} 2}$ mutant mice to study the impact of RyR2 KO on the heart. In the present study, we used the $\mathrm{crr}^{\mathrm{m} 1}$ mutant mice without subjecting them to Cre-mediated recombination.

\section{Western blot analysis}

The $c r r^{\mathrm{ml}}$ mutant and WT mouse hearts were frozen by a liquid $\mathrm{N}_{2}$-precooled Wollenberger clamp. The frozen heart tissues were ground to powder in the presence of liquid $\mathrm{N}_{2}$ and homogenated in the homogenizing buffer $\left(30 \mathrm{mM} \mathrm{KH}_{2} \mathrm{PO}_{4}, \mathrm{pH}\right.$ 7.0, $40 \mathrm{mM} \mathrm{NaF}, 5 \mathrm{mM}$ EDTA, $0.3 \mathrm{M}$ Sucrose, $4 \mu \mathrm{mol} / \mathrm{L}$ Leupeptin, $1 \mathrm{mM}$ Benzamidine, $100 \mu \mathrm{mol} / \mathrm{L}$ PMSF, $0.5 \mathrm{mM}$ DTT) using a precooled Brinkmann Polytron PT 15 homogenizer. The cell homogenate $(100 \mu \mathrm{l})$ was solubilized in a final $500 \mu \mathrm{l}$ buffer containing $3 \%$ SDS and $50 \mathrm{mM}$ Tris- $\mathrm{HCl}(\mathrm{pH} 7.5)$ at room temperature for one hour and incubated at $55^{\circ} \mathrm{C}$ for 10 minutes before centrifugation to remove unsolubilized materials. The solubilized proteins from WT or the $\mathrm{crr}^{\mathrm{ml}}$ mutant hearts were separated by $6 \%, 8 \%$ or $15 \%$ SDS-polyacrylamide gel electrophoresis (SDS-PAGE) and were transferred to nitrocellulose membranes at $100 \mathrm{~V}$ for 1.5 hours at $4{ }^{\circ} \mathrm{C}$ in the presence of $0.01 \%$ SDS $[29,30]$. The nitrocellulose membranes were then blocked for one hour with phosphate buffered saline (PBS: $137 \mathrm{mM} \mathrm{NaCl}, 8 \mathrm{mM} \mathrm{Na}_{2} \mathrm{HPO}_{4}, 1.5 \mathrm{mM} \mathrm{KH}_{2} \mathrm{PO}_{4}$ and $2.7 \mathrm{mM} \mathrm{KCl}, \mathrm{pH} 7.4$ ) containing $0.5 \%$ Tween- 20 and $5 \%$ skim milk powder. The membranes were incubated separately with the anti-RyR (34c, mouse), anti-Cav1.2 (rabbit), anti-SERCA (rabbit), anti-NCX (mouse), anti-CASQ2 (rabbit), or anti- $\beta$-actin (rabbit) antibodies (Thermo Fisher Scientific) to detect the expression level of major $\mathrm{Ca}^{2+}$ handling proteins. The membranes were washed three times with PBS containing $0.5 \%$ Tween-20 for 15 minutes before incubating with the corresponding secondary anti-IgG antibodies conjugated with horseradish peroxidase $(1: 20,000)$ (Thermo Fisher Scientific) for 30 minutes. The detection of the bound antibodies was enhanced by chemiluminescence kit from Pierce and visualized by ImageQuant LAS 4000 from GE Healthcare Life Sciences.

\section{Hematoxylin and eosin (H\&E) staining}

Hearts from the $c r r^{\mathrm{m} 1}$ mutant mice and their WT littermates were isolated and washed with Krebs-Ringers-HEPES (KRH) buffer ( $125 \mathrm{mM} \mathrm{NaCl}, 12.5 \mathrm{mM} \mathrm{KCl,} 25 \mathrm{mM}$ HEPES, pH 7.4, 6 $\mathrm{mM}$ glucose, and $1.2 \mathrm{mM} \mathrm{MgCl}_{2}$ ) and fixed with $4 \%$ paraformaldehyde solution via retrograde Langendorf perfusion system. The fixed hearts were cut across the long axis to show the four chambers and then put into tissue cassettes. The dehydrating, clearing and paraffining were 
performed using Leica ASP300S tissue processor. The paraffin embedded blocks were cut at $5 \mu \mathrm{m}$ thick and mounted onto slides, air-dried for 30 minutes at room temperature and were baked at $37^{\circ} \mathrm{C}$ overnight. The paraffin sections were deparaffinized by xylene and rehydrated through ethanol and tap water before labeling with hematoxylin. Three minutes after stained with hematoxylin, the slides were rinsed in 1\% acid alcohol (70\%) several times to remove free hematoxylin and then were immersed in PBS for dark-blue color reaction product. Thereafter, washed with distilled water and then stained with Eosin for 3 minutes. The H\&E stained slides were dehydrated in alcohol, cleared in xylene and mounted with coverslips. Photomicrographs were captured with a bright filed microscope (Olympus BX53).

\section{Electrocardiographic (ECG) recordings and induction of cardiac arrhythmias in anesthetized mice}

The $c r r^{\mathrm{m} 1}$ mutant and WT mice were lightly anesthetized with isoflurane vapor $(0.5-1 \%)$ and $95 \% \mathrm{O}_{2}$ and placed on a heating pad $\left(27^{\circ} \mathrm{C}\right)$. Two subcutaneous needle electrodes were inserted into the right upper limb and left lower abdomen for ECG recordings (BIOPAC MP System, Goleta, CA). The ECGs were continuously monitored under anesthesia until heart rate became stable. Baseline ECGs were recorded for 5-10 minutes before stimulation. For induction of ventricular arrhythmias, mutant mice and their WT littermates were subjected to intraperitoneal injection of epinephrine $(1.6 \mathrm{mg} / \mathrm{kg})$ and caffeine $(120 \mathrm{mg} / \mathrm{kg})$ (low dose), or were injected with $3.0 \mathrm{mg} / \mathrm{kg}$ epinephrine and $150 \mathrm{mg} / \mathrm{kg}$ caffeine (high dose). ECGs were continuously recorded for 30 minutes after the infusion of epinephrine and caffeine [31].

\section{Monophasic action potential (MAP) recordings in Langendorff-perfused hearts}

The $c r r^{\mathrm{m} 1}$ mutant and WT mice were sacrificed by cervical dislocation. Their hearts were cannulated to a Langendorff apparatus for maintaining coronary perfusion with oxygenated Tyrode's buffer (118 mM NaCl, $5.4 \mathrm{mM} \mathrm{KCl,} 25 \mathrm{mM} \mathrm{NaHCO}_{3}, 1 \mathrm{mM} \mathrm{MgCl}_{2}, 0.42 \mathrm{mM} \mathrm{NaH}_{2} \mathrm{PO}_{4}$, $11.1 \mathrm{mM}$ glucose, $10 \mathrm{mM}$ taurine, $5 \mathrm{mM}$ creatine, $\mathrm{pH} 7.4$ ) containing $1.8 \mathrm{mM} \mathrm{Ca}^{2+}$ at $35^{\circ} \mathrm{C}$. A monophasic action potential electrode was placed against the epicardial surface of the lower middle part of the left ventricle for epicardial MAP recording. Baseline MAP was recorded for 510 minutes before pacing at the right atrium from 5 to $10 \mathrm{~Hz}$ at $4-10 \mathrm{~V}$ for $>20$ seconds to induce APD alternans. The total length of the recording was 30 minutes. MAP signals were amplified by Gould amplifiers (models 13-G 4615-58, 13-4615-50 and 13-4615-71) and acquired at 2000 Hz/channel using a Data Translation (DT 2821) analog and digital input-output board. Analysis of MAP signals was performed using Acknowledgment (BIOPAC MP System, Goleta, CA).

\section{Laser scanning confocal $\mathrm{Ca}^{2+}$ imaging of intact hearts}

The $c r r^{\mathrm{ml}}$ mutant mice and WT littermates were sacrificed by cervical dislocation. Their hearts were cannulated to a Langendorff apparatus for maintaining coronary perfusion with oxygenated $\mathrm{Ca}^{2+}$ free Tyrode's buffer for 3-5 minutes and loaded with 4.4 $\mu \mathrm{M}$ Rhod-2 AM (Biotium, Inc. Hayward, CA) for about 45 minutes at $25^{\circ} \mathrm{C}[32,33]$. Extracellular $\mathrm{Ca}^{2+}$ was stepwise introduced to the heart from $0.25,0.5,1.0$, to $1.8 \mathrm{mM}$ in the presence of $5 \mu \mathrm{M}$ blebbistatin (Toronto Research Chemicals, Toronto, $\mathrm{ON}$ ) at $35^{\circ} \mathrm{C}$ throughout the experiment. The Langendorffperfused hearts were placed on a recording chamber mounted onto the Nikon A1R microscope for in situ confocal imaging (line-scan) of $\mathrm{Ca}^{2+}$ signals from epicardial ventricular myocytes. The pixel size of the resulting line-scan images ranged between 1.8 and $2 \mathrm{~ms}$ in the temporal dimension and between 0.1 to 0.4 microns in the spatial dimension. $\mathrm{Ca}^{2+}$ alternans was induced by rapid electrical stimulation of the hearts at increasing frequencies $(5-12 \mathrm{~Hz}, 6 \mathrm{~V})$. Data analysis was performed using NikonA1R analysis system and Image $\mathbf{J}$ software. 


\section{Image and signal processing}

The following signal and image processing methods were implemented using MATLAB (The Mathworks Inc., Boston, MA) as described previously [34, 35]. Briefly, Line-scan fluorescence images were filtered using a median filter applied iteratively a number of times according to an estimation of the image noise variance. Noise variance was robustly estimated by means of a median absolute deviation of the image pixels. Identification of individual cells in the line-scan was performed by manually labeling the cell regions. Average fluorescence signals of individual cells in each line-scan were automatically obtained by spatial averaging of the pixels belonging to each marked cell. Average fluorescence signals of single cells were further filtered by applying a continuous wavelet transform of the signal with Gaussian wavelets of order 2. Zerocrossing of the derivative of the resulting wavelet transform was used to accurately locate peaks and valleys in the fluorescence signals. Peaks were then classified as either stimulated or spontaneous using cross-correlation with the stimulation pulse train. Peak amplitudes were defined as the difference between the peak and the corresponding previous valley. For each cell, alternans ratio was measured as the ratio of the absolute value of the difference in amplitude between two consecutive peaks over the amplitude of the largest peak. The presence of alternans periods was established by requiring at least six consecutive stimulated peaks presenting an alternans ratio above 0.05 . For each cell, alternans duration was defined as the cumulative elapsed time of alternans periods over the total duration of the line-scan. The average alternans duration was determined by averaging alternans durations of all cells in one scan area; and the average alternans ratio was determined by averaging alternans ratios of cells that displayed alternans in the same scan area.

\section{Echocardiography}

Echocardiographic analysis of the WT and $\mathrm{crr}^{\mathrm{m} 1}$ mutant mice was carried out using the Vevo 770 echocardiography system equipped with a $30 \mathrm{MHz}$ transducer probe (Visual Sonics, Toronto, Canada) as described previously [36]. Mice (8-9 weeks old) were gently constrained on a heating pad $\left(37^{\circ} \mathrm{C}\right)$ and anesthetized with $1.5-2 \%$ isoflurane. Parameters, including the end systolic and diastolic diameters of the left chamber, interventricular septum and posterior wall thickness, left ventricular fractional shortening, and ejection fraction were analyzed for each mouse in a blinded manner involving the B-Mode and M-Mode measurements. All data were averaged from 10 cardiac cycles per mouse.

\section{Statistical Analysis}

All values shown are mean \pm SEM unless indicated otherwise. To test for differences between groups, we used unpaired Student's t-test (2-tailed) or one-way ANOVA with post hoc test. A P value $<0.05$ was considered to be statistically significant. 


\section{RESULTS}

\section{Modification of the ryr 2 gene for gene-targeted knock-out markedly reduces the protein expression of RyR2}

During the process of generating the RyR2 knock-out mice, Takeshima et al [19] previously produced a targeted mutant mouse $\left(c r r^{\mathrm{m} 1}\right)$, in which a $\operatorname{lox} P$ sequence was inserted into the 5'untranslation region, and a cassette containing a loxP sequence, the green fluorescence protein (GFP) cDNA, and the neomycin resistance gene (Neo) inserted into the first intron of the mouse $r y r 2$ gene (Fig. 1A). Although these insertions in the intron sequences generally have minimal impact on gene organization and expression, surprisingly, we found that homozygous $\mathrm{crr}^{\mathrm{m} 1}$ mutant mice displayed markedly reduced expression of the RyR 2 protein. Immunoblotting analyses of whole heart lysates revealed that the expression level of the RyR2 protein in the $c r{ }^{\mathrm{m} 1}$ mutant hearts was substantially reduced compared with that in the WT hearts $(23.3 \pm 4.5 \%$ vs WT, $\mathrm{p}<0.01$ ) (Fig. 1B, C). On the other hand, there were no significant differences in the expression levels of other major $\mathrm{Ca}^{2+}$ handling proteins between the $c r r^{\mathrm{m} 1}$ mutant and WT hearts, including the L-type $\mathrm{Ca}^{2+}$ channel, $\mathrm{Na}^{+} / \mathrm{Ca}^{2+}$ exchanger, the sarco/endoplasmic reticulum $\mathrm{Ca}^{2+}$ ATPase (SERCA), and calsequestrin (CASQ2) (Fig. 1B, C). Therefore, the crr $^{\mathrm{m} 1}$ mutant mice express a markedly reduced level of RyR2 protein, and represent a useful model for studying the impact of reduced RyR2 protein expression.

\section{Reducing RyR2 protein expression protects against stress-induced ventricular tachyarrhythmia}

It has been suggested that the level of RyR2 protein may play an important role in determining the susceptibility to catecholaminergic polymorphic ventricular tachycardia (CPVT) $[22,24,37]$. However, direct evidence for the role of RyR2 protein expression in CPVT is lacking. To this end, we took advantage of the $c r r^{\mathrm{m} 1}$ mouse model to assess the impact of reduced RyR2 WT protein expression on stress-induced ventricular tachyarrhythmia (VT). We monitored the occurrence of VTs in WT and $c r r^{\mathrm{m} 1}$ mutant mice using electrocardiography (ECG) recordings before and after the injection of a mixture of caffeine $(120 \mathrm{mg} / \mathrm{kg})$ and epinephrine $(1.6 \mathrm{mg} / \mathrm{kg})$. This combination of pharmacological reagents has been widely used to trigger VTs in mouse models of CPVT [31, 33, 38-40]. Consistent with those reported previously, WT mice showed short-durations of VTs $(5.7 \pm 4.1 \%)$ over the 30 -min period of ECG recordings after the injection of these triggers (Fig. 2A, E, F). Interestingly, not a single episode of VTs was detected in the $c r r^{\mathrm{m} 1}$ mutant mice under the same conditions (Fig. 2C, E, F). These observations raise the possibility that the $c r r^{\mathrm{m} 1}$ mutant mice may be protected against stress-induced VTs. To test this hypothesis, we repeated the stress tests in WT and $c r r^{\mathrm{m} 1}$ mutant mice using higher doses of caffeine $(150 \mathrm{mg} / \mathrm{kg})$ and epinephrine $(3.0 \mathrm{mg} / \mathrm{kg})$. As expected, high doses of caffeine and epinephrine induced severe polymorphic and bidirectional VTs in WT mice with an average VT duration of $46.3 \pm 16.0 \%$ over the 30 -min period of ECG recordings (Fig. 2B, E, F). Remarkably, the $c r r^{\mathrm{m} 1}$ mutant mice showed no VTs at all after the injection of high doses of caffeine and epinephrine (Fig. 2D, E, F). Thus, the $c r r^{\mathrm{m} 1}$ mutant mice are resistant to stress-induced VTs. Taken together, these observations indicate that reducing RyR2 WT protein expression can protect against stress-induced VTs in mice.

\section{Reducing RyR2 protein promotes $\mathrm{Ca}^{2+}$ alternans in intact hearts}

We have previously shown that inhibiting the luminal $\mathrm{Ca}^{2+}$ activation of RyR2 suppresses stress-induced VTs, but enhances $\mathrm{Ca}^{2+}$ alternans [35]. It is possible that reducing the expression of the RyR2 protein, which suppresses stress-induced VTs, may also affect $\mathrm{Ca}^{2+}$ alternans. To test this possibility, we assessed the intracellular $\mathrm{Ca}^{2+}$ dynamics in intact working WT and the $c r r^{\mathrm{m} 1}$ 
mutant hearts stimulated at increasing frequencies $(5-10 \mathrm{~Hz})$ using in situ confocal laser scanning $\mathrm{Ca}^{2+}$ imaging. Figure 3 shows representative images and traces of $\mathrm{Ca}^{2+}$ transients obtained from WT and the $c r r^{\mathrm{m} 1}$ mutant hearts stimulated at $7 \mathrm{~Hz}$. At this stimulation frequency, little or no $\mathrm{Ca}^{2+}$ alternans was detected in the WT hearts (Fig. 3A), whereas, the $c r r^{\mathrm{m} 1}$ mutant hearts showed severe $\mathrm{Ca}^{2+}$ alternans (Fig. 3B). The average duration of $\mathrm{Ca}^{2+}$ alternans was $80.2 \pm 4.6 \%$ in the $\mathrm{crr}^{\mathrm{m} 1}$ mutant hearts versus $10.6 \pm 3.0 \%$ in the WT hearts. The average alternans ratio was $57.3 \pm 4.4 \%$ in the $c r r^{\mathrm{m} 1}$ mutant hearts versus $5.8 \pm 1.7 \%$ in the WT hearts (Fig. 3C,D). Furthermore, the threshold stimulation frequency at which $\mathrm{Ca}^{2+}$ alternans occurred was lower in the $\mathrm{crr}^{\mathrm{m} 1}$ mutant hearts than in the WT hearts (Fig. 4). $\mathrm{Ca}^{2+}$ alternans was readily detected in the $\mathrm{crr}^{\mathrm{m} 1}$ mutant hearts at a stimulation frequency of $5 \mathrm{~Hz}$, whereas, higher stimulation frequencies $(8-10 \mathrm{~Hz})$ were required to induce $\mathrm{Ca}^{2+}$ alternans in WT hearts (Fig. 4). Moreover, the $\mathrm{crr}^{\mathrm{m} 1}$ mutant hearts displayed significantly longer alternans durations and higher alternans ratios at 5-10 $\mathrm{Hz}$ compared with the WT hearts at the same stimulation frequencies (Fig. 4A,B). It should be noted that reducing RyR2 protein expression also affected the properties of $\mathrm{Ca}^{2+}$ transients. The $\mathrm{crr}^{\mathrm{m} 1}$ mutant hearts showed significantly increased time-to-peak and decay time $\left(\mathrm{T}_{50}\right)$, but similar amplitude of $\mathrm{Ca}^{2+}$ transients compared to WT hearts (Fig. 5). Collectively, these observations indicate that reduced RyR2 protein expression enhances the susceptibility to $\mathrm{Ca}^{2+}$ alternans.

\section{Reducing RyR2 protein enhances action potential duration alternans}

We next determined whether reduced RyR2 protein expression affects the propensity for action potential duration (APD) alternans. Monophasic action potential (MAP) was recorded in Langendorff-perfused WT and the $c r r^{\mathrm{m} 1}$ mutant hearts. The hearts were stimulated with increasing frequencies from 5 to $10 \mathrm{~Hz}$ to induce action potential duration alternans. As shown in Fig. 6, WT hearts showed little or no APD alternans at the stimulation frequency of $8 \mathrm{~Hz}$ (Fig. 6A), whereas, the $c r r^{\mathrm{m} 1}$ mutant hearts exhibited significant APD alternans at the same stimulation frequency $(8$ $\mathrm{Hz}$ ) (Fig. 6B). As the stimulation frequency increased from 5 to $10 \mathrm{~Hz}$, the ratios of APD alternans increased in both the WT and the $c r r^{\mathrm{m} 1}$ mutant hearts (Fig. 6C). However, the APD alternans ratio in the $c r r^{\mathrm{m} 1}$ mutant hearts was significantly higher than that in the WT hearts at each stimulation frequency (between 6-10 Hz). For instance, at $8 \mathrm{~Hz}$, the average APD alternans ratio was $2.6 \pm$ $0.9 \%$ in WT hearts and $19.5 \pm 5.6 \%$ in the $\mathrm{crr}^{\mathrm{m} 1}$ mutant hearts (Fig. 6C). These results indicate that reduced RyR2 protein expression enhances the susceptibility to APD alternans.

\section{The crr $^{\mathrm{m} 1}$ mutant mice display cardiac hypertrophy and sudden death}

Tissue-specific, conditional KO of RyR2 in the heart resulted in cardiac hypertrophy and sudden death [20]. To determine whether constitutively reducing RyR2 protein expression can lead to cardiac hypertrophy and sudden death, we assessed and compared the weights of the WT and $c r r^{\mathrm{m} 1}$ mutant hearts of the WT and $c r r^{\mathrm{m} 1}$ mutant mice. Hematoxylin and eosin (H\&E) staining of paraformaldehyde fixed heart sections revealed increased thickness of the ventricular walls (Fig. 7A) and ventricular cell area (Fig. 7B,C) in the $c r r^{\mathrm{m} 1}$ mutant hearts compared with those in WT hearts. Consistent with these observations, echocardiographic analyses also revealed increased ventricular wall thickness in the $c r r^{\mathrm{m} 1}$ mutant hearts compared with the WT hearts (Table 1). Furthermore, the $\mathrm{crr}^{\mathrm{m} 1}$ mutant mice showed a significant increase in the heart weight-to-body weight ratio compared with the WT mice $\left(56.0 \pm 2.8 \%\right.$ in $\mathrm{crr}^{\mathrm{m} 1}$ vs $40.7 \pm 2.6 \%$ in WT) (Fig. 7D). Similar to that observed with the conditional RyR2 KO mice [20], we also found that the crr $^{\mathrm{m} 1}$ mutant mice exhibited sudden death at young ages, starting at 40 days (Fig. 8). On the other hand, no sudden death was observed with the WT mice (Fig. 8). Taken together, these results indicate that reducing RyR2 protein expression can lead to cardiac hypertrophy and increase the incidence of sudden death. 


\section{DISCUSSION}

Although reduced RyR2 protein expression is likely to occur under various cardiac conditions, the impact of reduced RyR2 protein level on cardiac function is not well understood. In the present study, we exploited a mutant mouse model with reduced RyR2 protein expression. We found that reducing the protein expression of RyR2 suppresses stress-induced VTs, but enhances $\mathrm{Ca}^{2+}$ alternans and APD alternans. In addition, reduced RyR2 protein expression led to cardiac hypertrophy and increased the susceptibility to sudden death. These findings provide novel insights into the role of RyR2 protein expression in VTs and cardiac alternans.

A remarkable finding from the present study is that mice with reduced RyR2 WT protein expression are resistant to stress-induced VTs, suggesting that the level of RyR2 WT protein expression can affect the propensity for stress-induced VTs. It has been shown that the severity of CPVT phenotypes in individuals with the same RyR2 mutations (e.g. deletion of exon-3 or G357S) can differ substantially [23, 25-28]. Although the exact mechanism underlying the phenotypic variability in the same families or in individuals with the same mutations is unknown, our finding suggests that reduced RyR2 protein expression may be one of the many factors that determine the penetrance of CPVT. It is possible that some CPVT-linked RyR2 mutations alter not only the gating properties of RyR2, but also its protein expression, which would in turn affect the propensity for CPVT. In support of this view, we have previously shown that deletion of exon-3 and the point mutation G357S markedly reduce the protein expression of RyR2, which may contribute to the incomplete penetrance of CPVT in individuals with these mutations [22-24]. Interestingly, Bongianino et al [37] recently employed RNA interference to specifically reduce the protein expression of the RyR2 mutant allele in a CPVT mouse model expressing the RyR2 mutation R4496C. They found that allelic silencing of the RyR2 R4496C mutant expression is able to prevent CPVT in these mice. These observations suggest that reducing the expression of the RyR2 mutant protein represents a promising strategy for the treatment of CPVT. Our data would further suggest that reducing the expression level of the total RyR2 protein (both WT and mutant) may also be protective against CPVT. In this regard, it would be of great interest to determine whether individuals with nonsense or frame-shift RyR2 mutations that result in haploinsufficiency display reduced or enhanced susceptibility to CPVT.

It is important to note that suppressed RyR2 activity has been shown to enhance cardiac alternans [35]. Furthermore, reduced RyR2 protein expression has been implicated in the genesis of cardiac alternans [21]. Consistent with these observations, we found that reducing the protein expression of RyR2 indeed increases the propensity for $\mathrm{Ca}^{2+}$ and AP-duration alternans. Hence, although reducing the level of RyR2 protein expression can suppress stress-induced VTs, it can also increase the propensity for $\mathrm{Ca}^{2+}$ and APD alternans, a well-known cause of re-entrant arrhythmias that can lead to ventricular fibrillation and sudden death. Therefore, reducing the protein expression of RyR2 has the beneficial effect of suppressing stress-induced VTs, but the adverse effect of promoting cardiac alternans. Since cardiac alternans usually occurs at fast heart rates, one may be able to minimize the adverse effect of reduced RyR2 protein expression on cardiac alternans by controlling the heart rate. It is also important to note that reduced RyR2 protein expression also increases the risk of developing cardiac hypertrophy and sudden death [20]. Hence, a future challenge would be to fine tune the protein expression of RyR 2 , in addition to normalizing the activity of RyR2, in order to maximize its suppressing effect on stress-induced VTs, while minimize its adverse effect on cardiac alternans, hypertrophy, and sudden death.

The exact mechanism by which reducing RyR2 expression protects against stress-induced ventricular tachyarrhythmias (VTs), but promotes $\mathrm{Ca}^{2+}$ and APD alternans is unknown. It has been shown that enhanced RyR2 function can increase the propensity for spontaneous SR $\mathrm{Ca}^{2+}$ release, which in turn can lead to delayed afterdepolarization, triggered activity, and VTs $[2,3]$. On the other hand, depressed RyR2 function can prolong the refractoriness of $\mathrm{SR} \mathrm{Ca}^{2+}$ release, which in 
turn can increase the propensity for $\mathrm{Ca}^{2+}$ alternans [41-44]. Consistent with these observations, we have previously shown that a RyR2 mutation E4872Q that reduces the activity of RyR2 by suppressing $\mathrm{Ca}^{2+}$ activation of the channel and spontaneous $\mathrm{SR} \mathrm{Ca}^{2+}$ release protects against stressinduced VTs. On the other hand, the depressed E4872Q mutation prolongs the refractoriness of SR $\mathrm{Ca}^{2+}$ release and promotes $\mathrm{Ca}^{2+}$ alternans and APD alternans. It is likely that the rate of $\mathrm{SR} \mathrm{Ca}^{2+}$ release would depend on the level of the RyR2 protein, such that reducing RyR2 protein expression to some extent may mimic the depression or reduction in RyR2 function. In line with this view, we found that reducing RyR2 protein expression indeed decreases the rate of rise of $\mathrm{Ca}^{2+}$ transients. Hence, it is possible that like the depressed RyR2 mutant E4872Q, reducing RyR2 protein expression may suppress spontaneous $\mathrm{SR} \mathrm{Ca}^{2+}$ release and prolong $\mathrm{SR} \mathrm{Ca}^{2+}$ release refractoriness. However, further investigations are needed to test these hypotheses.

In summary, the present study demonstrates that reducing the protein expression of RyR2 suppresses stress-induced VTs. This effect of reduced RyR2 protein expression on VTs may contribute to the incomplete penetrance of CPVT. Reduced RyR 2 protein expression also increases the propensity for cardiac alternans, hypertrophy, and sudden death. Therefore, although moderate reduction in RyR2 protein expression may protect against CPVT, severe RyR2 protein reduction may lead to adverse effects.

\title{
ACKNOWLEDGEMENTS:
}

This work was supported by research grants from the Canadian Institutes of Health Research, the Heart and Stroke Foundation of Canada, the Canada Foundation for Innovation, and the Heart and Stroke Foundation Chair in Cardiovascular Research (to SRWC). This study was also supported by the Spanish Ministry of Economy and Competitiveness SAF2014-58286-C2-1-R (LH-M) and DPI2013-44584-R (RB). We would also like to thank Dr. Long-Sheng Song, University of Iowa, for his continuous support and helpful discussion on intact heart $\mathrm{Ca}^{2+}$ imaging, and the Libin Core Pathology Laboratory, Cumming School of Medicine, the University of Calgary, for H\&E staining of the WT and mutant mouse heart tissues.

CONFLICT OF INTEREST: The authors declare that they have no conflicts of interest with the contents of this article.

AUTHOR CONTRIBUTIONS: XZ, AV, BS, ZX, WG, JW, YC, EO, AG, LHM, RB, DB, SRWC designed the research; XZ, BS, ZX, WG, JW, YC, DB performed the research; XZ, AV, BS, ZX, JW, YC, LHM, RB, DB, SRWC analyzed data; MI, HT provided research reagents, and $\mathrm{XZ}, \mathrm{AV}, \mathrm{BS}, \mathrm{LHM}, \mathrm{RB}, \mathrm{SRWC}$ wrote the paper.

\author{
ABBREVIATIONS USED: \\ CPVT, Catecholaminergic Polymorphic Ventricular Tachycardia \\ RyR2, Cardiac Ryanodine Receptor \\ SR, Sarcoplasmic Reticulum \\ VT, Ventricular Tachyarrhythmia \\ ECG, Electrocardiography \\ MAP, Monophasic Action Potential \\ APD, Action Potential Duration \\ SERCA2a, Sarco/endoplasmic Reticulum $\mathrm{Ca}^{2+}$ ATPase \\ CASQ2, Cardiac Calsequestrin
}


Table 1

Table 1. Echocardiographic analyses of WT and crr $^{\mathrm{m} 1}$ mutant mice

\begin{tabular}{lcc}
\hline & WT & crr $^{\mathrm{m} 1}$ \\
\hline LVS d $(\mathbf{m m})$ & $0.63 \pm 0.02$ & $0.84 \pm 0.06^{* *}$ \\
LVS s (mm) & $0.93 \pm 0.04$ & $1.20 \pm 0.05^{* *}$ \\
LVPW d(mm) & $0.73 \pm 0.06$ & $0.84 \pm 0.05^{*}$ \\
LVPW s(mm) & $0.93 \pm 0.03$ & $1.19 \pm 0.03^{* *}$ \\
FS (\%) & $31.63 \pm 2.81$ & $25.79 \pm 3.6^{\mathrm{ns}}$ \\
EF $(\%)$ & $59.50 \pm 4.02$ & $50.65 \pm 5.71^{\mathrm{ns}}$ \\
Number of mic & 10 & 6 \\
\hline
\end{tabular}

$* \mathrm{p}<0.05 ; * * \mathrm{p}<0.01$. Data shown are mean \pm SEM.

LVS d, interventricular septum thickness at end diastole; LVS s, interventricular septum thickness at end systole; LVPW d, left ventricular posterior wall thickness at end diastole; LVPW s, left ventricular posterior wall thickness at end systole; FS, fractional shortening. EF, ejection fraction. 


\section{REFERENCES}

1 Bers, D. M. (2002) Cardiac excitation-contraction coupling. Nature. 415, 198-205.

2 Priori, S. G. and Chen, S. R. (2011) Inherited dysfunction of sarcoplasmic reticulum $\mathrm{Ca}^{2+}$ handling and arrhythmogenesis. Circulation research. 108, 871-883

3 Maclennan, D. H. and Zvaritch, E. (2011) Mechanistic models for muscle diseases and disorders originating in the sarcoplasmic reticulum. Biochimica et biophysica acta. 1813, 948-964

$4 \quad$ Ai, X., Curran, J. W., Shannon, T. R., Bers, D. M. and Pogwizd, S. M. (2005)

$\mathrm{Ca}^{2+} /$ Calmodulin-Dependent Protein Kinase Modulates Cardiac Ryanodine Receptor Phosphorylation and Sarcoplasmic Reticulum $\mathrm{Ca}^{2+}$ Leak in Heart Failure. Circ Res. 97, 1314-1322

5 Terentyev, D., Gyorke, I., Belevych, A. E., Terentyeva, R., Sridhar, A., Nishijima, Y., de Blanco, E. C., Khanna, S., Sen, C. K., Cardounel, A. J., Carnes, C. A. and Gyorke, S. (2008) Redox modification of ryanodine receptors contributes to sarcoplasmic reticulum $\mathrm{Ca}^{2+}$ leak in chronic heart failure. Circulation research. 103, 1466-1472

6 Belevych, A. E., Radwanski, P. B., Carnes, C. A. and Gyorke, S. (2013) 'Ryanopathy': causes and manifestations of RyR2 dysfunction in heart failure. Cardiovasc Res. 98, 240247PMC3633158

7 Jiang, D., Xiao, B., Zhang, L. and Chen, S. R. (2002) Enhanced basal activity of a cardiac $\mathrm{Ca}^{2+}$ release channel (ryanodine receptor) mutant associated with ventricular tachycardia and sudden death. Circ Res. 91, 218-225.

8 Jiang, D., Xiao, B., Yang, D., Wang, R., Choi, P., Zhang, L., Cheng, H. and Chen, S. R. W. (2004) RyR2 mutations linked to ventricular tachycardia and sudden death reduce the threshold for store-overload-induced $\mathrm{Ca}^{2+}$ release (SOICR). Proc.Natl.Acad.Sci.U.S.A. 101, 13062-13067

9 Jiang, D., Wang, R., Xiao, B., Kong, H., Hunt, D. J., Choi, P., Zhang, L. and Chen, S. R. W. (2005) Enhanced Store Overload-Induced $\mathrm{Ca}^{2+}$ Release and Channel Sensitivity to Luminal $\mathrm{Ca}^{2+}$ Activation Are Common Defects of RyR2 Mutations Linked to Ventricular Tachycardia and Sudden Death. Circ Res. 97, 1173-1181

10 Jiang, D., Chen, W., Wang, R., Zhang, L. and Chen, S. R. W. (2007) Loss of luminal Ca ${ }^{2+}$ activation in the cardiac ryanodine receptor is associated with ventricular fibrillation and sudden death. Proceedings of the National Academy of Sciences of the United States of America. 104, 18309-18314

11 Jiang, D., Jones, P. P., Davis, D. R., Gow, R., Green, M. S., Birnie, D. H., Chen, S. R. and Gollob, M. H. (2010) Characterization of a novel mutation in the cardiac ryanodine receptor that results in catecholaminergic polymorphic ventricular tachycardia. Channels (Austin, Tex.). 4, 302-310

12 Tang, Y., Tian, X., Wang, R., Fill, M. and Chen, S. R. (2012) Abnormal termination of Ca ${ }^{2+}$ release is a common defect of RyR2 mutations associated with cardiomyopathies. Circulation research. 110, 968-977

13 Naudin, V., Oliviero, P., Rannou, F., Sainte Beuve, C. and Charlemagne, D. (1991) The density of ryanodine receptors decreases with pressure overload- induced rat cardiac hypertrophy. FEBS Lett. 285, 135-138

14 Rannou, F., Dambrin, G., Marty, I., Carre, F., Trouve, P., Lompre, A. M. and Charlemagne, D. (1996) Expression of the cardiac ryanodine receptor in the compensated phase of hypertrophy in rat heart. Cardiovasc Res. 32, 258-265

15 Sainte Beuve, C., Allen, P. D., Dambrin, G., Rannou, F., Marty, I., Trouve, P., Bors, V., Pavie, A., Gandgjbakch, I. and Charlemagne, D. (1997) Cardiac calcium release channel 
(ryanodine receptor) in control and cardiomyopathic human hearts: mRNA and protein contents are differentially regulated. J Mol Cell Cardiol. 29, 1237-1246

16 Yamamoto, T., Yano, M., Kohno, M., Hisaoka, T., Ono, K., Tanigawa, T., Saiki, Y., Hisamatsu, Y., Ohkusa, T. and Matsuzaki, M. (1999) Abnormal Ca ${ }^{2+}$ release from cardiac sarcoplasmic reticulum in tachycardia-induced heart failure. Cardiovasc Res. 44, 146-155

17 Voigt, N., Heijman, J., Wang, Q., Chiang, D. Y., Li, N., Karck, M., Wehrens, X. H., Nattel, S. and Dobrev, D. (2014) Cellular and molecular mechanisms of atrial arrhythmogenesis in patients with paroxysmal atrial fibrillation. Circulation. 129, 145-156

18 Chiang, D. Y., Kongchan, N., Beavers, D. L., Alsina, K. M., Voigt, N., Neilson, J. R., Jakob, H., Martin, J. F., Dobrev, D., Wehrens, X. H. and Li, N. (2014) Loss of microRNA-106b-25 cluster promotes atrial fibrillation by enhancing ryanodine receptor type- 2 expression and calcium release. Circulation.Arrhythmia and electrophysiology. 7, 1214-1222

19 Takeshima, H., Komazaki, S., Hirose, K., Nishi, M., Noda, T. and Iino, M. (1998) Embryonic lethality and abnormal cardiac myocytes in mice lacking ryanodine receptor type 2. Embo J. 17, 3309-3316

20 Bround, M. J., Asghari, P., Wambolt, R. B., Bohunek, L., Smits, C., Philit, M., Kieffer, T. J., Lakatta, E. G., Boheler, K. R., Moore, E. D., Allard, M. F. and Johnson, J. D. (2012) Cardiac ryanodine receptors control heart rate and rhythmicity in adult mice. Cardiovascular research. 96, 372-380

21 Wan, X., Laurita, K. R., Pruvot, E. J. and Rosenbaum, D. S. (2005) Molecular correlates of repolarization alternans in cardiac myocytes. Journal of Molecular and Cellular Cardiology. 39, 419-428

22 Liu, Y., Wang, R., Sun, B., Mi, T., Zhang, J., Mu, Y., Chen, J., Bround, M. J., Johnson, J. D., Gillis, A. M. and Chen, S. R. (2014) Generation and characterization of a mouse model harboring the exon-3 deletion in the cardiac ryanodine receptor. PLoS One. 9, e95615PMC3990712

23 Wanguemert, F., Bosch Calero, C., Perez, C., Campuzano, O., Beltran-Alvarez, P., Scornik, F. S., Iglesias, A., Berne, P., Allegue, C., Ruiz Hernandez, P. M., Brugada, J., Perez, G. J. and Brugada, R. (2015) Clinical and molecular characterization of a cardiac ryanodine receptor founder mutation causing catecholaminergic polymorphic ventricular tachycardia. Heart rhythm : the official journal of the Heart Rhythm Society. 12, 1636-1643

24 Liu, Y., Wei, J., Wong King Yuen, S. M., Sun, B., Tang, Y., Wang, R., Van Petegem, F. and Chen, S. R. W. (2017) CPVT-associated cardiac ryanodine receptor mutation G357S with reduced penetrance impairs $\mathrm{Ca}^{2+}$ release termination and diminishes protein expression. PLoS One. 12, e0184177PMC5621672

25 Bhuiyan, Z. A., van den Berg, M. P., van Tintelen, J. P., Bink-Boelkens, M. T., Wiesfeld, A. C., Alders, M., Postma, A. V., van Langen, I., Mannens, M. M. and Wilde, A. A. (2007) Expanding spectrum of human RYR2-related disease: new electrocardiographic, structural, and genetic features. Circulation. 116, 1569-1576

26 Medeiros-Domingo, A., Bhuiyan, Z. A., Tester, D. J., Hofman, N., Bikker, H., van Tintelen, J. P., Mannens, M. M., Wilde, A. A. and Ackerman, M. J. (2009) The RYR2-encoded ryanodine receptor/calcium release channel in patients diagnosed previously with either catecholaminergic polymorphic ventricular tachycardia or genotype negative, exerciseinduced long QT syndrome: a comprehensive open reading frame mutational analysis. Journal of the American College of Cardiology. 54, 2065-2074

27 Marjamaa, A., Laitinen-Forsblom, P., Lahtinen, A. M., Viitasalo, M., Toivonen, L., Kontula, K. and Swan, H. (2009) Search for cardiac calcium cycling gene mutations in familial ventricular arrhythmias resembling catecholaminergic polymorphic ventricular tachycardia. BMC medical genetics. 10, 12 
28 Ohno, S., Omura, M., Kawamura, M., Kimura, H., Itoh, H., Makiyama, T., Ushinohama, H., Makita, N. and Horie, M. (2014) Exon 3 deletion of RYR2 encoding cardiac ryanodine receptor is associated with left ventricular non-compaction. Europace : European pacing, arrhythmias, and cardiac electrophysiology : journal of the working groups on cardiac pacing, arrhythmias, and cardiac cellular electrophysiology of the European Society of Cardiology

29 Laemmli, U. K. (1970) Cleavage of structural proteins during the assembly of the head of bacteriophage T4. Nature. 227, 680-665.

30 Towbin, H., Staehelin, T. and Gordon, J. (1979) Electrophoretic transfer of proteins from polyacrylamide gels to nitrocellulose sheets: procedure and some applications. Proc Natl Acad Sci U S A. 76, 4350-4434.

31 Zhou, Q., Xiao, J., Jiang, D., Wang, R., Vembaiyan, K., Wang, A., Smith, C. D., Xie, C., Chen, W., Zhang, J., Tian, X., Jones, P. P., Zhong, X., Guo, A., Chen, H., Zhang, L., Zhu, W., Yang, D., Li, X., Chen, J., Gillis, A. M., Duff, H. J., Cheng, H., Feldman, A. M., Song, L. S., Fill, M., Back, T. G. and Chen, S. R. (2011) Carvedilol and its new analogs suppress arrhythmogenic store overload-induced $\mathrm{Ca}^{2+}$ release. Nature medicine. 17, 1003-1009

32 Chen, B., Guo, A., Gao, Z., Wei, S., Xie, Y. P., Chen, S. R., Anderson, M. E. and Song, L. S. (2012) In situ confocal imaging in intact heart reveals stress-induced $\mathrm{Ca}\left({ }^{2+}\right)$ release variability in a murine catecholaminergic polymorphic ventricular tachycardia model of type 2 ryanodine receptor(R4496C+/-) mutation. Circulation. Arrhythmia and electrophysiology. 5, 841-849

33 Chen, W., Wang, R., Chen, B., Zhong, X., Kong, H., Bai, Y., Zhou, Q., Xie, C., Zhang, J., Guo, A., Tian, X., Jones, P. P., O'Mara, M. L., Liu, Y., Mi, T., Zhang, L., Bolstad, J., Semeniuk, L., Cheng, H., Zhang, J., Chen, J., Tieleman, D. P., Gillis, A. M., Duff, H. J., Fill, M., Song, L. S. and Chen, S. R. (2014) The ryanodine receptor store-sensing gate controls $\mathrm{Ca}\left({ }^{2+}\right)$ waves and $\mathrm{Ca}\left({ }^{2+}\right)$-triggered arrhythmias. Nature medicine. 20, 184-192

34 Bai, Y., Jones, P. P., Guo, J., Zhong, X., Clark, R. B., Zhou, Q., Wang, R., Vallmitjana, A., Benitez, R., Hove-Madsen, L., Semeniuk, L., Guo, A., Song, L. S., Duff, H. J. and Chen, S. R. (2013) Phospholamban knockout breaks arrhythmogenic $\mathrm{Ca}^{2+}$ waves and suppresses catecholaminergic polymorphic ventricular tachycardia in mice. Circulation research. 113, $517-526$

35 Zhong, X., Sun, B., Vallmitjana, A., Mi, T., Guo, W., Ni, M., Wang, R., Guo, A., Duff, H. J., Gillis, A. M., Song, L. S., Hove-Madsen, L., Benitez, R. and Chen, S. R. (2016) Suppression of Ryanodine Receptor Function Prolongs $\mathrm{Ca}^{2+}$ Release Refractoriness and Promotes Cardiac Alternans in Intact Hearts. The Biochemical journal

36 Brodehl, A., Belke, D. D., Garnett, L., Martens, K., Abdelfatah, N., Rodriguez, M., Diao, C., Chen, Y. X., Gordon, P. M., Nygren, A. and Gerull, B. (2017) Transgenic mice overexpressing desmocollin-2 (DSC2) develop cardiomyopathy associated with myocardial inflammation and fibrotic remodeling. PLoS One. 12, e0174019PMC5365111

37 Bongianino, R., Denegri, M., Mazzanti, A., Lodola, F., Vollero, A., Boncompagni, S., Fasciano, S., Rizzo, G., Mangione, D., Barbaro, S., Di Fonso, A., Napolitano, C., Auricchio, A., Protasi, F. and Priori, S. G. (2017) Allele Specific Silencing of Mutant mRNA Rescues Ultrastructural and Arrhythmic Phenotype in Mice Carriers of the R4496C Mutation in the Ryanodine Receptor Gene (RYR2). Circ Res

38 Priori, S. G., Napolitano, C., Tiso, N., Memmi, M., Vignati, G., Bloise, R., Sorrentino, V. V. and Danieli, G. A. (2001) Mutations in the Cardiac Ryanodine Receptor Gene (hRyR2) Underlie Catecholaminergic Polymorphic Ventricular Tachycardia. Circulation. 103, 196200. 
39 Zhang, J., Chen, B., Zhong, X., Mi, T., Guo, A., Zhou, Q., Tan, Z., Wu, G., Chen, A. W., Fill, M., Song, L. S. and Chen, S. R. (2014) The cardiac ryanodine receptor luminal $\mathrm{Ca}^{2+}$ sensor governs $\mathrm{Ca}^{2+}$ waves, ventricular tachyarrhythmias and cardiac hypertrophy in calsequestrin-null mice. The Biochemical journal. 461, 99-106

40 Zhang, J., Zhou, Q., Smith, C. D., Chen, H., Tan, Z., Chen, B., Nani, A., Wu, G., Song, L. S., Fill, M., Back, T. G. and Chen, S. R. (2015) Non-beta-blocking R-carvedilol enantiomer suppresses $\mathrm{Ca}^{2+}$ waves and stress-induced ventricular tachyarrhythmia without lowering heart rate or blood pressure. The Biochemical journal. 470, 233-242

41 Diaz, M. E., Eisner, D. A. and O'Neill, S. C. (2002) Depressed Ryanodine Receptor Activity Increases Variability and Duration of the Systolic $\mathrm{Ca}^{2+}$ Transient in Rat Ventricular Myocytes. Circ Res. 91, 585-593

42 Pieske, B. and Kockskamper, J. (2002) Alternans goes subcellular: a "disease" of the ryanodine receptor? Circulation research. 91, 553-555

43 Picht, E., DeSantiago, J., Blatter, L. A. and Bers, D. M. (2006) Cardiac alternans do not rely on diastolic sarcoplasmic reticulum calcium content fluctuations. Circulation research. 99, 740-748

44 Wang, L., Myles, R. C., De Jesus, N. M., Ohlendorf, A. K., Bers, D. M. and Ripplinger, C. M. (2014) Optical mapping of sarcoplasmic reticulum $\mathrm{Ca}^{2+}$ in the intact heart: ryanodine receptor refractoriness during alternans and fibrillation. Circulation research. 114, 1410-1421 
FIGURES AND LEGENDS

Fig.1

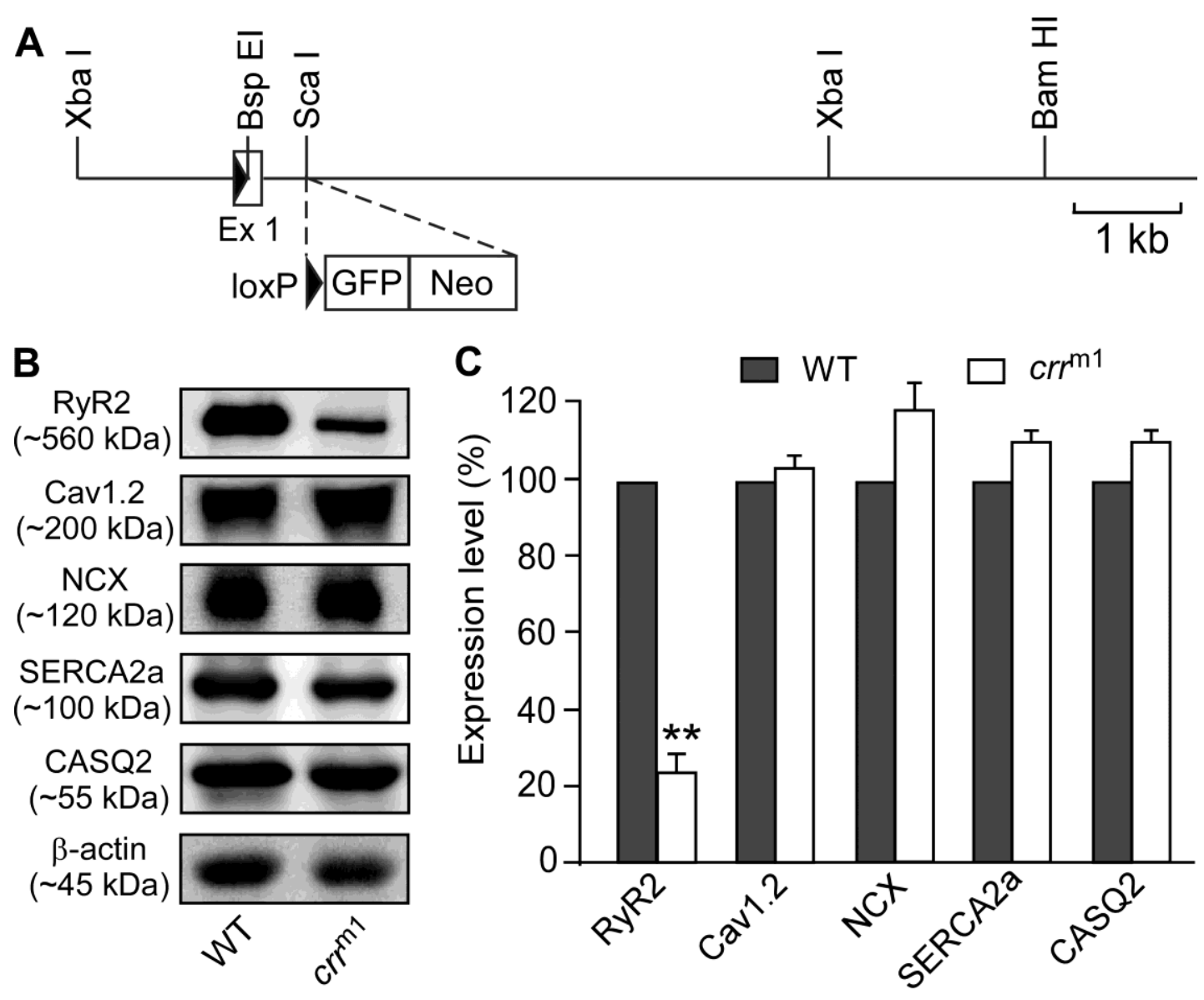

Figure 1. The crr $^{\mathrm{m} 1}$ mutant mice display reduced $\mathrm{RyR} 2$ protein expression.

(A) Genetic manipulations in the mouse $r y r 2$ gene are illustrated [19]. The loxP sequence was introduced into the BspEI site in exon 1 (Ex 1) and the loxP-GFP-Neo cassette was inserted into the ScaI site in intron 1 after exon 1. (B) Western blot analysis of RyR2, Cav1.2, NCX, SERCA2a, CASQ2, and $\beta$-actin expression in the $c r r^{\mathrm{m} 1}$ mutant and WT hearts. The same amount of heart lysate proteins was loaded in each lane, and the bands were detected using the corresponding antibodies $(\mathrm{n}=3-4)$. (C) The expression level of each protein in the $c r r^{\mathrm{m} 1}$ mutant hearts was normalized to that of the WT hearts. Data shown are mean \pm SEM $(n=3-4)(* * P<$ $0.01)$. 
Fig. 2

A WT mice

Before Epi/caff injection
After Epi/caff $(1.6 \mathrm{mg} / 120 \mathrm{mg}$, low dose) injection

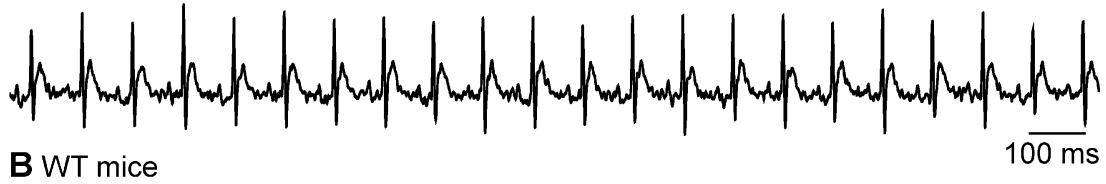

Before Epi/caff injection

After Epi/caff $(3.0 \mathrm{mg} / 150 \mathrm{mg}$, high dose) injection
$100 \mathrm{~ms}$

corrm1 mutant mice

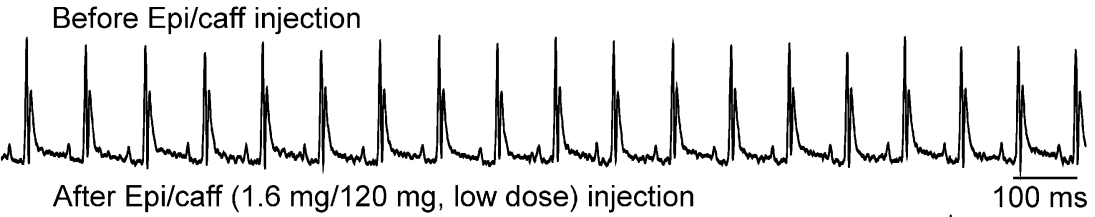

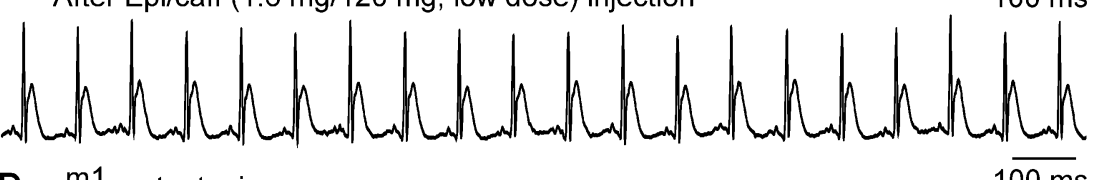

D $\mathrm{crr}^{\mathrm{m} 1}$ mutant mice

Before Epi/caff injection
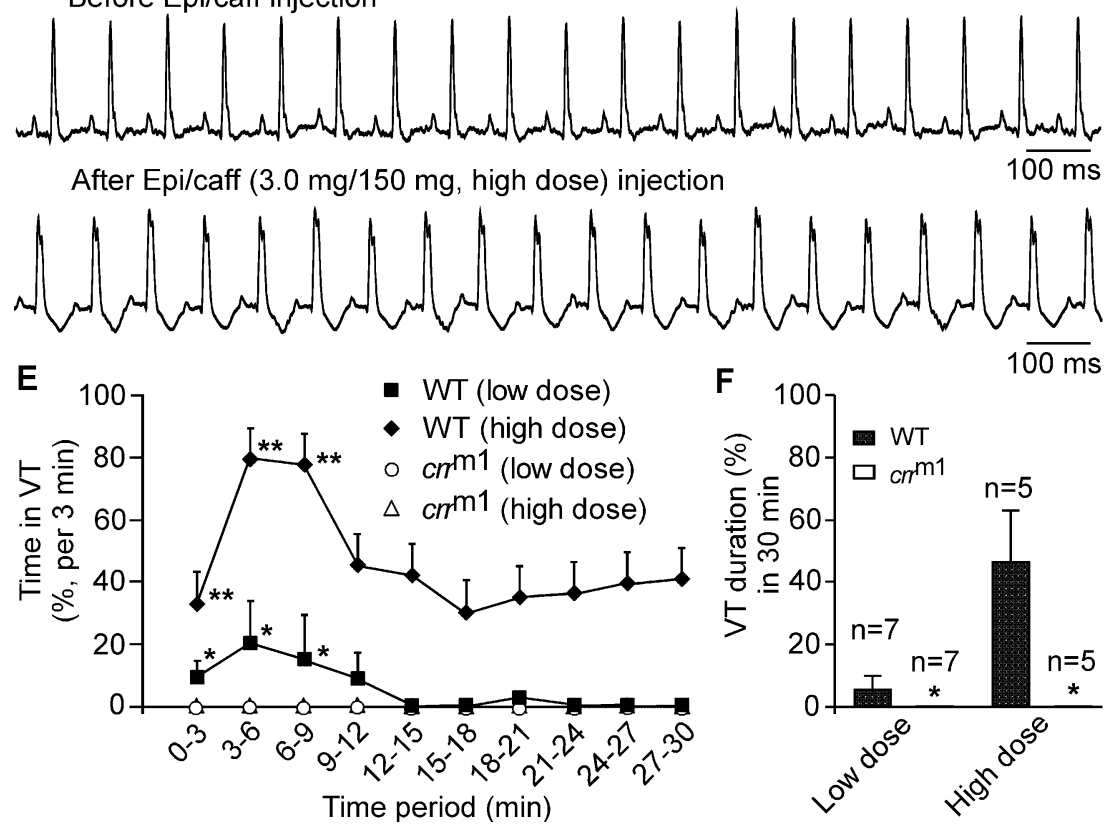

Figure 2. The crr $^{\mathrm{m} 1}$ mutant mice are resistant to stress-induced VTs. 
ECGs were recorded in anesthetized RyR2 WT and the $c r r^{\mathrm{m} 1}$ mutant mice. The mice were injected (i.p.) with $120 \mathrm{mg} / \mathrm{kg}$ caffeine plus $1.6 \mathrm{mg} / \mathrm{kg}$ epinephrine (low dose) or $150 \mathrm{mg} / \mathrm{kg}$ caffeine plus $3.0 \mathrm{mg} / \mathrm{kg}$ epinephrine (high dose). ECGs were recorded for another 30 minutes after injection. Representative ECG traces of the RyR2 WT mice (A, B) and the $c r r^{\mathrm{m} 1}$ mutant mice $(\mathrm{C}$, D) before and after injection of low dose $(A, C)$ or high dose $(B, D)$ of caffeine and epinephrine. The VT duration (\%) in the RyR2 WT or the $c r r^{\mathrm{m} 1}$ mutant mice within each 3-min period (E) or within the 30-min period (F) of ECG recordings are shown. Data shown are mean \pm SEM ( $n=7$ for the low dose group, $\mathrm{n}=5$ for the high dose group) ( $* \mathrm{P}<0.05, * * \mathrm{P}<0.01)$. 
Fig.3

A Wildtype heart paced at $7 \mathrm{~Hz}$
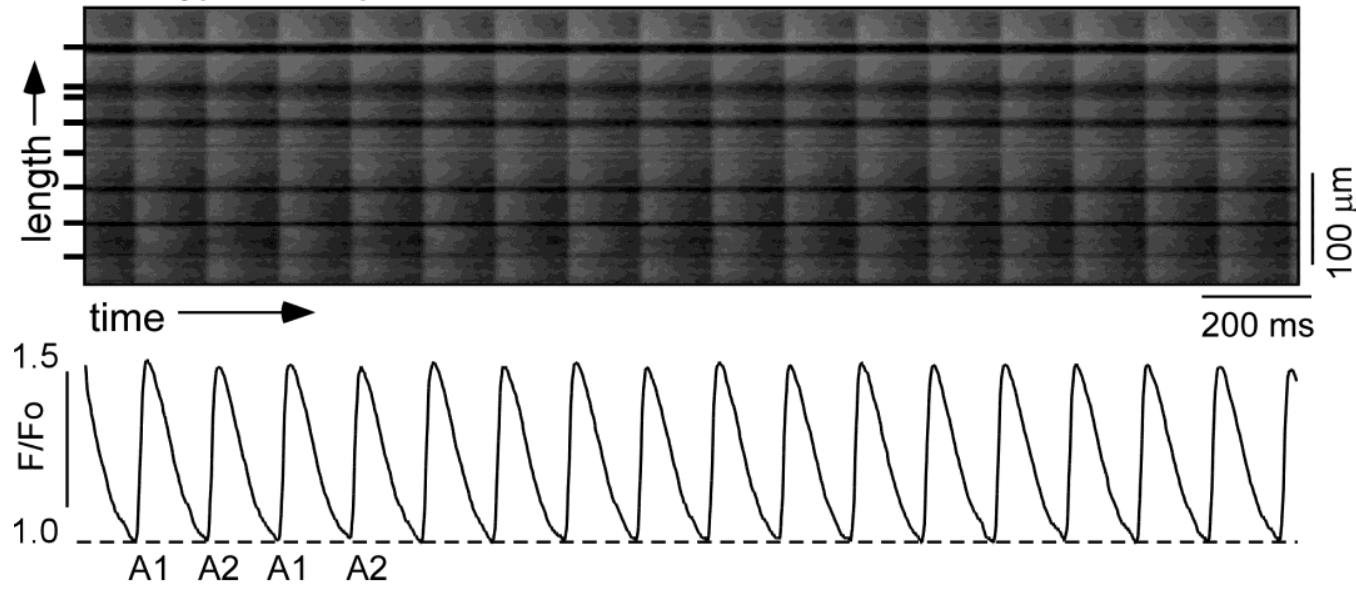

B $c r r^{m 1}$ mutant heart paced at $7 \mathrm{~Hz}$
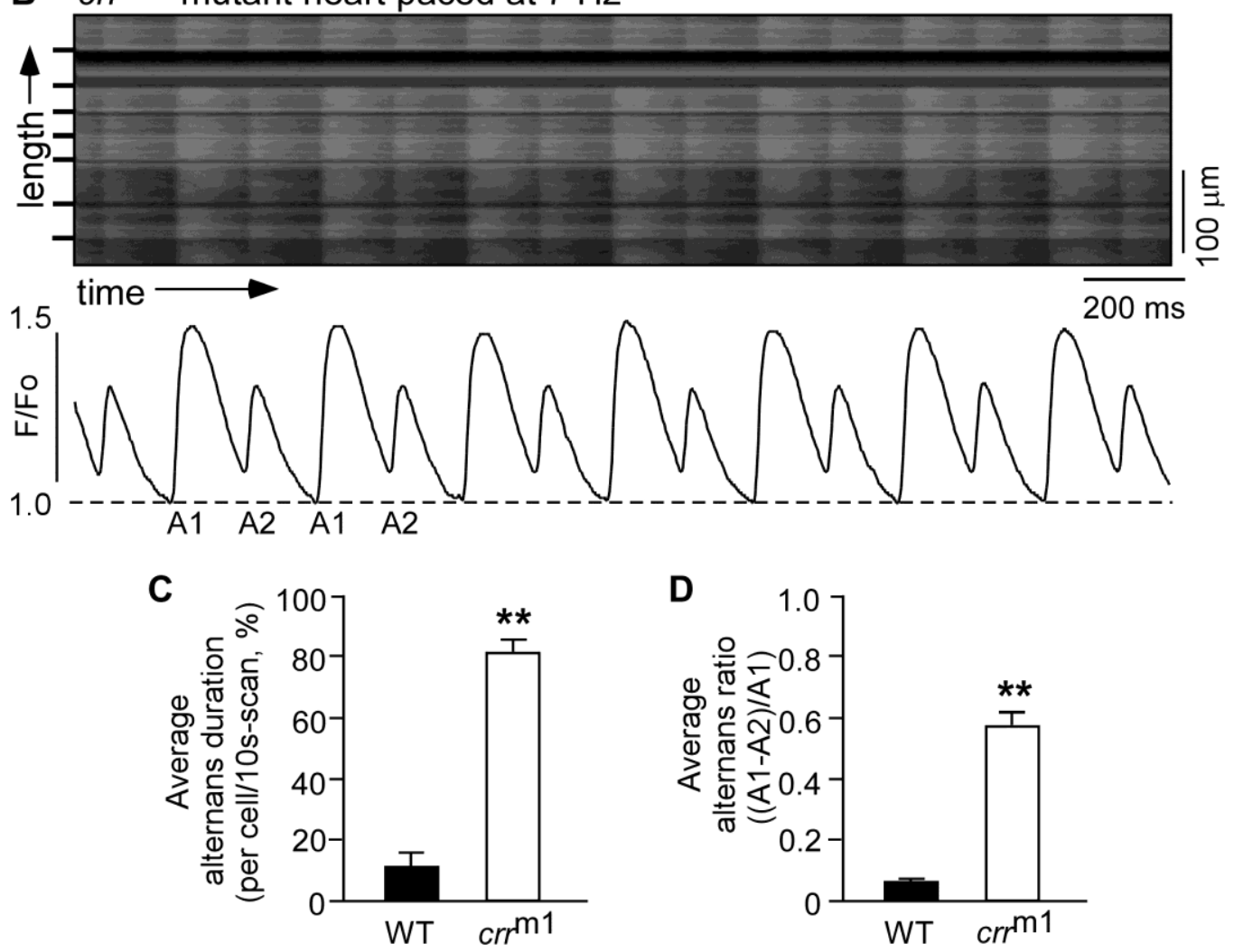

Figure 3. $\mathrm{Ca}^{2+}$ alternans in intact $\mathrm{WT}$ and $\mathrm{crr}^{\mathrm{m} 1}$ mutant hearts paced at $7 \mathrm{~Hz}$.

Intact WT (A) and the $c r r^{\mathrm{m} 1}$ mutant (B) hearts were loaded with Rhod-2 AM and perfused with blebbistatin in a Langendorff setting. $\mathrm{Ca}^{2+}$ transients were elicited by pacing at $7 \mathrm{~Hz}$ and recorded using laser confocal imaging in the line-scanning mode. Cell boundaries were indicated by short bars on the left. The F/Fo traces depict the average fluorescence signal of the scan area. Alternans duration for each cell in the scan area and alternans ratio for each cell that displayed alternans in the same scan area were determined and averaged per cell to yield the average alternans duration (C) and average alternans ratio (D). Alternans duration is defined as the percentage of time in alternans over the 10s scanning period, and alternans ratio is defined as the 
ratio of the difference in amplitude between the large and small $\mathrm{Ca}^{2+}$ transients over the amplitude of the large $\mathrm{Ca}^{2+}$ transient. Data shown are mean \pm SEM $(\mathrm{n}=14$ scan areas from $6 \mathrm{WT}$ hearts, $\mathrm{n}=$ 20 scan areas from $7 \mathrm{crr}^{\mathrm{m} 1}$ mutant hearts) $(* * \mathrm{p}<0.01)$. 
Fig. 4
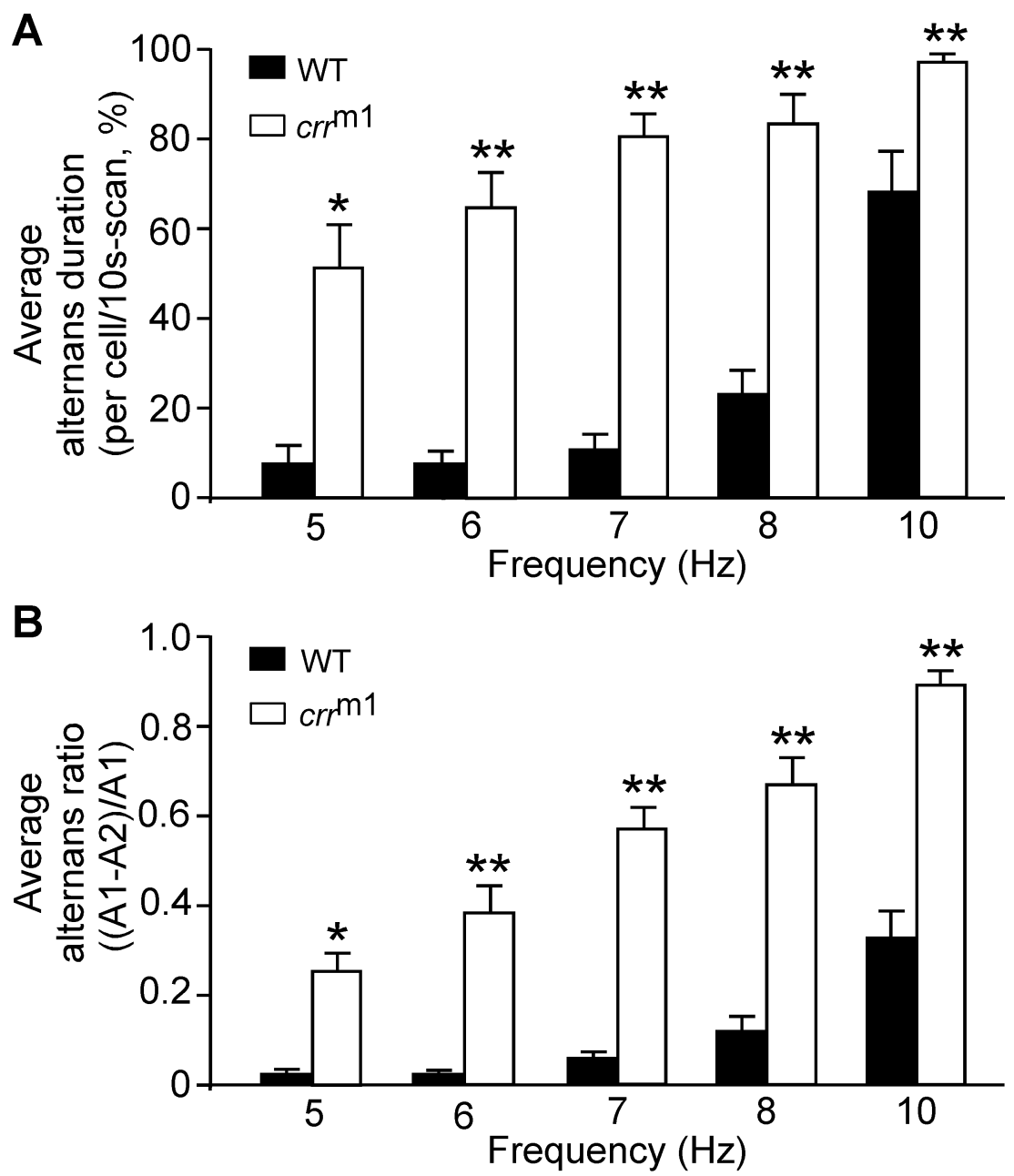

Figure 4. Average alternans duration and average alternans ratio at different pacing frequencies in intact WT and crr $^{\mathrm{m1}}$ mutant hearts.

Intact WT and $c r r^{\mathrm{m} 1}$ mutant hearts were loaded with Rhod-2 AM and perfused with blebbistatin in a Langendorff setting. $\mathrm{Ca}^{2+}$ transients were elicited by pacing at different frequencies from 5 to $10 \mathrm{~Hz}$, and recorded using laser confocal imaging in the line-scanning mode. (A) Average alternans duration (\%) in cells in WT or the $c r r^{\mathrm{m} 1}$ mutant hearts over the 10s scanning period. (B) The average alternans ratio for cells that displayed alternans. Data shown are mean \pm SEM ( $\mathrm{n}=14$ scan areas from 6 RyR2 WT hearts, $\mathrm{n}=20$ scan areas from $7 \mathrm{crr}^{\mathrm{m} 1}$ mutant hearts) $(* \mathrm{p}<0.05, * * \mathrm{p}<0.01)$. 
Fig. 5

A Wildtype heart paced at $5 \mathrm{~Hz}$
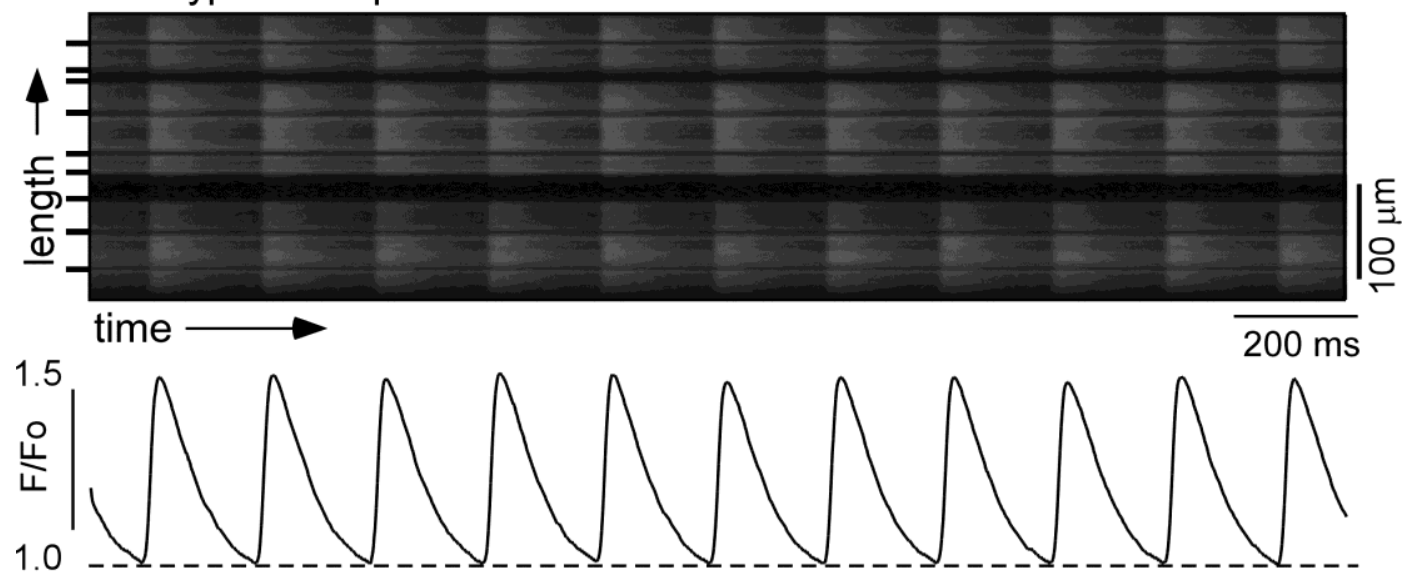

B $c r r^{m 1}$ mutant heart paced at $5 \mathrm{~Hz}$
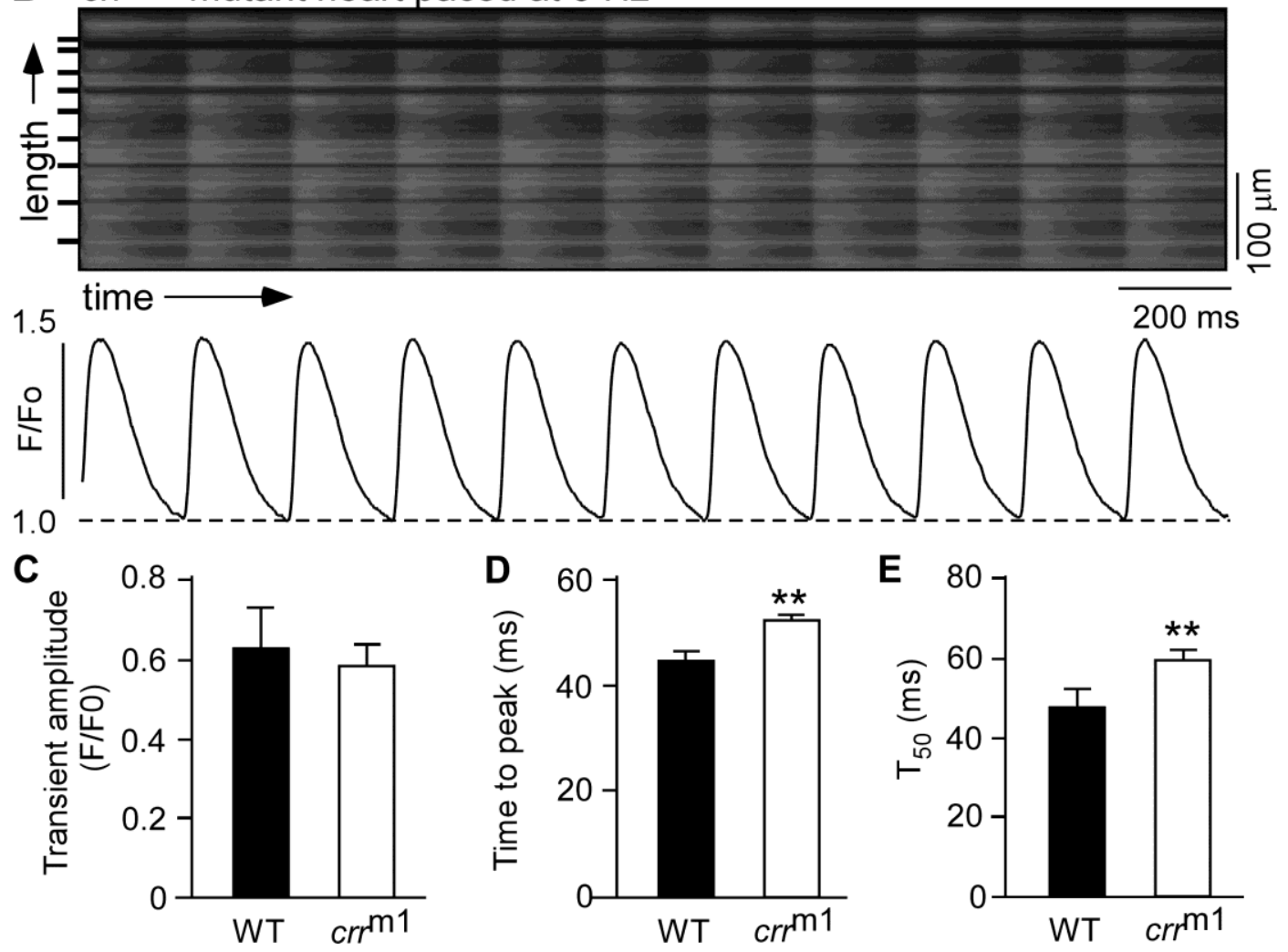

Figure 5. $\mathrm{Ca}^{2+}$ transient properties of the $\mathrm{WT}$ and $\mathrm{crr}^{\mathrm{m} 1}$ mutant hearts

Intact WT (A) and the $c r r^{\mathrm{ml}}$ mutant (B) hearts were loaded with Rhod-2 AM and perfused with blebbistatin in a Langendorff setting. $\mathrm{Ca}^{2+}$ transients were elicited by pacing at $5 \mathrm{~Hz}$ and recorded using laser confocal imaging in the line-scanning mode. Cell boundaries were indicated by short bars on the left. The F/Fo traces depict the average fluorescence signal of the scan area. The average transient amplitude (C), time-to-peak (D), and decay time $\left(\mathrm{T}_{50}\right) \mathrm{Of}^{\mathrm{Ca}^{2+}}$ transients in the WT and $c r r^{\mathrm{ml}}$ mutant hearts are indicated. Data shown are mean \pm SEM ( $\mathrm{n}=4$ scan areas from 2 RyR2 WT hearts, $\mathrm{n}=13$ scan areas from $7 \mathrm{crr}^{\mathrm{ml}}$ mutant hearts) $(* * \mathrm{p}<0.01)$. 
Fig. 6

A Wildtype heart paced at $8 \mathrm{~Hz}$

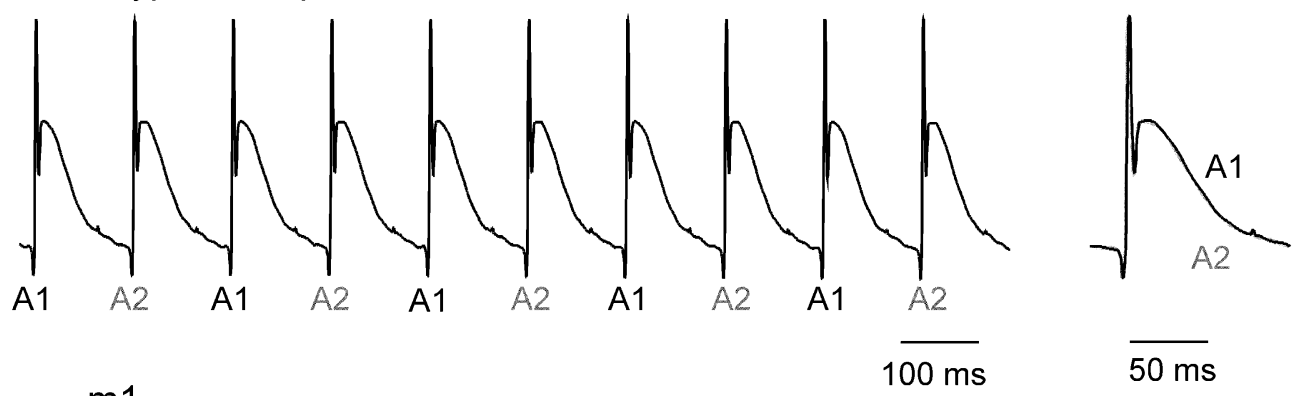

B $\mathrm{crr}^{\mathrm{m} 1}$ mutant heart paced at $8 \mathrm{~Hz}$
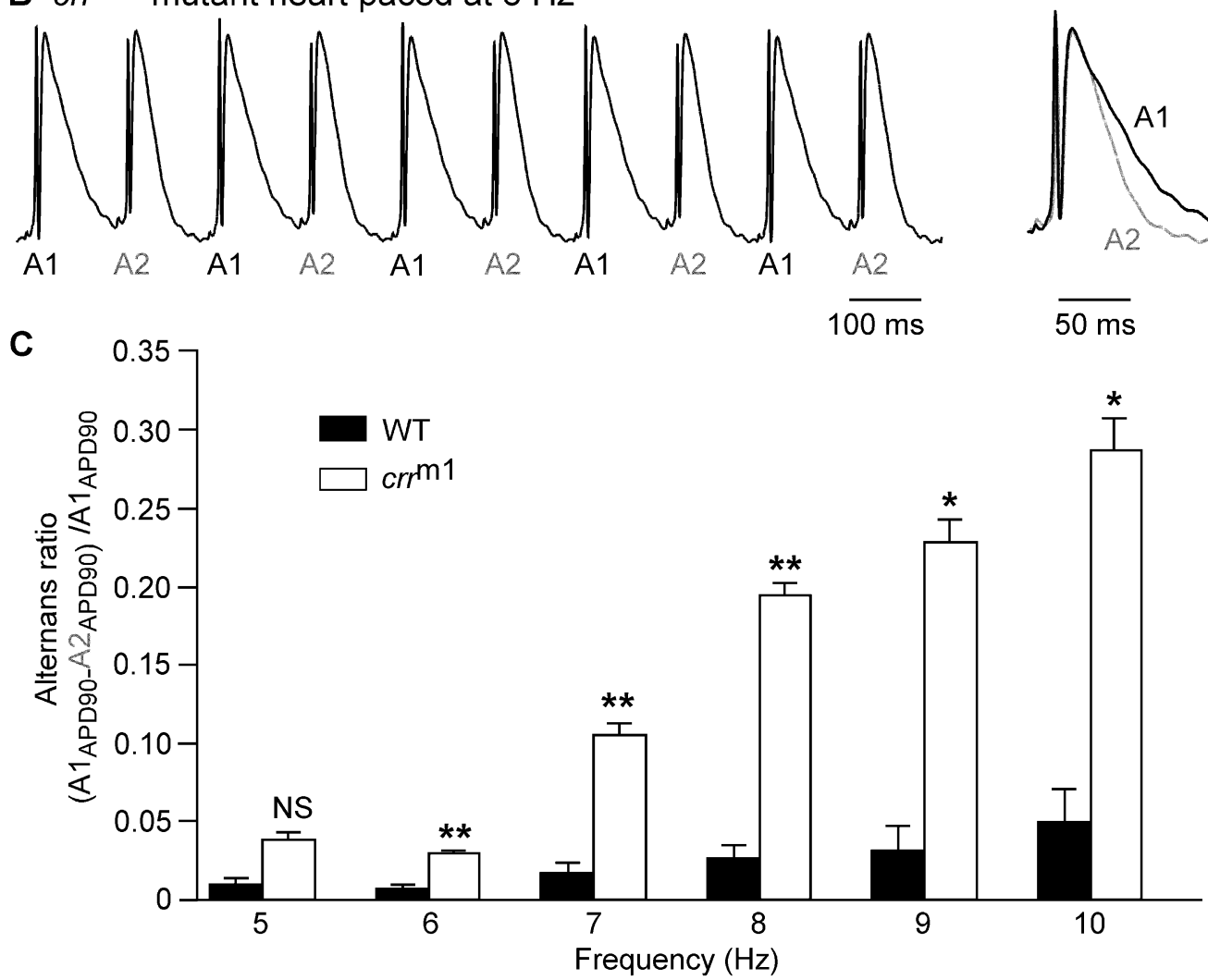

Figure 6. The $c r^{\mathrm{m} 1}$ mutant hearts are more susceptible to APD alternans.

The WT and $c r r^{\mathrm{m} 1}$ mutant hearts were stimulated with increasing frequencies $(5-10 \mathrm{~Hz})$ at 5-10 V to induce APD alternans. Representative traces of MAP recordings from WT hearts (A) and the $c r r^{\mathrm{m} 1}$ mutant hearts (B) paced at $8 \mathrm{~Hz}$ are shown. (C) The APD alternans ratios of the WT and the $c r r^{\mathrm{m} 1}$ mutant hearts paced at different frequencies $(5-10 \mathrm{~Hz})$. Data shown are mean \pm $\operatorname{SEM}\left(\mathrm{n}=6\right.$ for WT hearts, $\mathrm{n}=4$ for the $c r r^{\mathrm{m} 1}$ mutant hearts) $\left({ }^{*} \mathrm{p}<0.05,{ }^{*} \mathrm{p}<0.01\right)$. 
Fig. 7

A
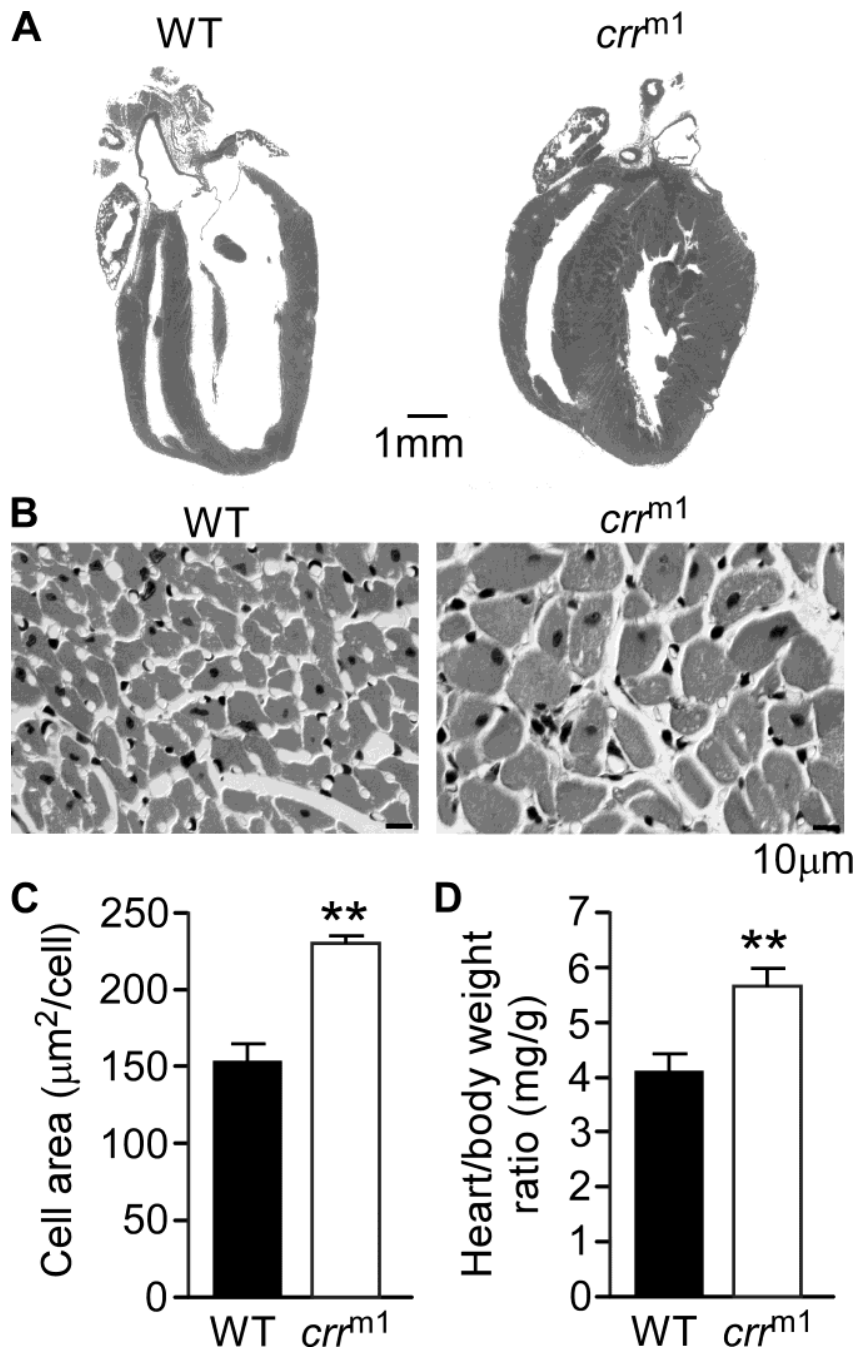

Figure 7. The $\boldsymbol{c r r}^{\mathrm{m} 1}$ mutant mice show cardiac hypertrophy

(A) Representative sections of the WT and $c r r^{\mathrm{m} 1}$ mutant hearts stained with hematoxylin and eosin (H\&E). (B) H\&E stained and transversal sectioned myocardium from the free wall of the left ventricle. (C) The myocardium cell area in WT and $c r r^{\mathrm{m} 1}$ mutant hearts. (D) The heart- and bodyweight ratios of the WT and $c r r^{\mathrm{m} 1}$ mutant hearts. Data shown are mean $\pm \mathrm{SEM}(\mathrm{n}=4$ for WT, $\mathrm{n}=$ 6 for $c r r^{\mathrm{m} 1}$ mutant mice) $(* * \mathrm{P}<0.01)$. 


\section{Figure 8}

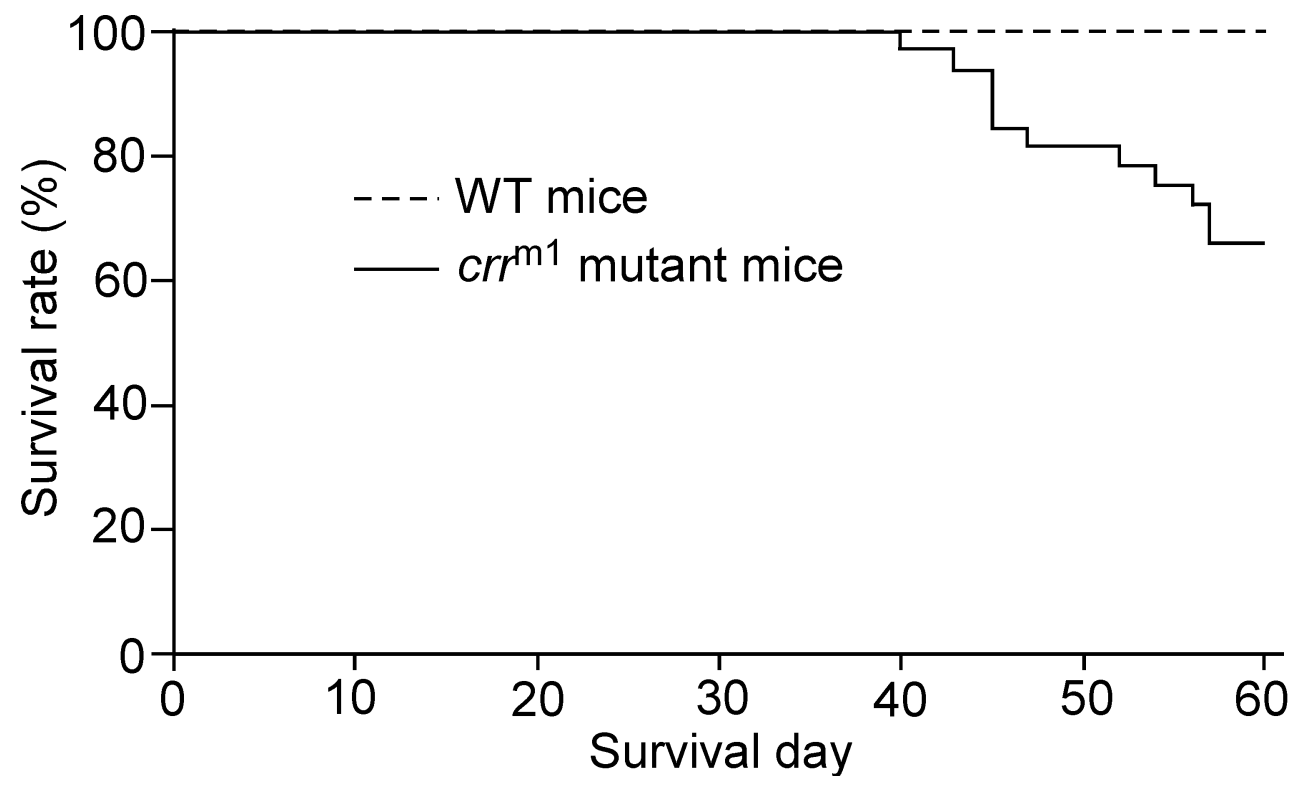

Figure 8. The crr $^{\mathrm{m} 1}$ mutant mice died suddenly at young ages.

The survival rate of the $c r r^{\mathrm{m} 1}$ mutant mice $(\mathrm{n}=32)$ and the WT mice $(\mathrm{n}=22)$ is shown. Note that no WT mice died during the period (60 days) of observation, whereas, the $c r r^{\mathrm{m} 1}$ mutant mice started to die at the age of 40 days. 